NSL 02893

\title{
PATHOGENESIS OF HYPOXIC-ISCHEMIC BRAIN INJURY IN A PERINATAL RODENT MODEL
}

\author{
FAYE SILVERSTEIN, KAREN BUCHANAN and MICHAEL V. JOHNSTON* \\ Department of Pediatrics and Neurology, University of Michigan Medical School and Center for Human \\ Growth and Development, Ann Arbor, MI 48109 (U.S.A.)
}

(Received March 26th, 1984; Accepted May 11th, 1984)

Key words: hypoxia-ischemia - immature rat - cerebral blood flow - $\left[{ }^{14} \mathrm{C}\right]$ iodoantipyrine

Exposure of immature rats to $8 \%$ oxygen after unilateral carotid artery ligation (UCL) causes metabolic, neurochemical and histopathological changes in the ipsilateral forebrain that resemble those in human perinatal hypoxic-ischemic encephalopathy. Regional cerebral perfusion in this model was examined by visual analysis of India ink trapped in cerebral vessels and measurement of $\left[{ }^{14} \mathrm{C}\right]$ iodoantipyrine $\left(\left[{ }^{14} \mathrm{C}\right] \mathrm{IAP}\right)$ and $\left[{ }^{3} \mathrm{H}\right]$ flunitrazepam extraction into the brain. $\mathrm{UCL}$ alone reduced $\left[{ }^{14} \mathrm{C}\right] \mathrm{IAP}$ accumulation in the ipsilateral hemisphere by $20 \%$ and hypoxia superimposed on UCL progressively reduced ipsilateral hemisphere perfusion by $71 \%$ at $2 \mathrm{~h}$. Hypoxia probably injures neurons in this model by causing a critical reduction in cerebral perfusion, an effect which also appears to be important in the human disorder.

Perinatal asphyxia in human infants damages developing central neurons and myelin in a selective fashion [4, 6]. However, until recently, no reproducible small animal model for this disorder was available [10]. Rice et al. [11] demonstrated that in one-week-old rats subjected to unilateral common carotid artery ligation, subsequent exposure to $8 \%$ oxygen reliably injures the cerebral hemisphere on the side of ligation. Hypoxia or carotid ligation alone has no discernable effect. The basal ganglia (caudate-putamen and globus pallidum) on the injured side are especially vulnerable and histopathology observed in animals allowed to mature resembles closely that found in humans [7]. Furthermore, acute time-dependent changes in energy substrate [18] and dopamine [15] metabolism have been correlated with the topography of injury, making it possible to examine the biochemical pathogenesis of the neuronal insult.

To characterize the mechanism of injury in the preparation, we examined changes in cerebral perfusion during the hypoxic period. In contrast to results from similar procedures in adult animals [13], we found that hypoxia causes a progressive reduc-

\footnotetext{
*Author for correspondence at: Neuroscience Lab Building, 1103 East Huron, Ann Arbor, MI 48109, U.S.A.
} 
tion in hemisphere perfusion ipsilateral to the occluded carotid. The mechanism of brain injury in the immature rodent replicates pathophysiologic features which appear to be important in human perinatal hypoxia-ischemia [17].

Seven-day-old rat pups were anesthetized briefly with ether and the right or left common carotid artery was ligated. Pups were allowed to recover with the dam for $2 \mathrm{~h}$ and then placed along with sham-operated controls in a humidified $8 \%$ oxygen balance nitrogen atmosphere inside a warmed glass vessel $\left(37^{\circ} \mathrm{C}\right)$ for time intervals of 0 to $120 \mathrm{~min}$. For analysis of brain perfusion, the pups were removed quickly from the chamber, then either India ink, $\left[{ }^{14} \mathrm{C}\right]$ iodoantipyrine $\left(\left[{ }^{14} \mathrm{C}\right] \mathrm{IAP}\right)$ or $\left[{ }^{3} \mathrm{H}\right]$ flunitrazepam was injected into the left ventricle of the heart and pups were killed $10 \mathrm{~s}$ later.

Hypoperfusion induced by 30 or 60 min of hypoxia in the brains of carotid ligated pups was grossly obvious after India ink perfusion (Fig. 1). Ink filled vessels symmetrically in normoxic unilaterally ligated animals but sacrifice at intervals during hypoxia demonstrated progressive pallor on the occluded side. It is noteworthy that at $30 \mathrm{~min}$, pallor was confined to a localized region in the periventricular white matter region which is especially vulnerable in human infants [2].

To quantitate the perfusion changes during hypoxia, groups of pups were analyzed after intracardiac injections of $\left[{ }^{14} \mathrm{C}\right] \mathrm{IAP},(49.8 \mathrm{mCi} / \mathrm{mmol}$; $\mathrm{NEN})$ an established marker for blood flow [12] or $\left[{ }^{3} \mathrm{H}\right]$ flunitrazepam $(78 \mathrm{Ci} / \mathrm{mmol}$; Amersham) a rapidly extracted compound with characteristics of a 'liquid microsphere' [5]. Conventional procedures for measuring regional cerebral blood flow require simultaneous measurements of brain and arterial concentrations of the extracted markers. However, since the circulating blood volume of the rat pup is about $0.6 \mathrm{ml}(5 \%$ of body weight), withdrawal of volumes adequate for sampling would significantly lower blood volume and possibly cerebral perfusion. Therefore, we standardized a method using timed, bolus injections. In pilot experiments, $1 \mu \mathrm{Ci}$ of either tracer, dissolved in $50 \mu \mathrm{l}$ of water, was injected into the left ventricle of the heart through a 26-gauge needle and pups were decapitated at 10-20 s intervals during the following minute. The brains were dissected on ice, and samples of striatum, adjacent frontolateral cortex and pons-medulla were removed, weighed and dissolved in NCS tissue solubilizer (Amersham). Accumulation of extracted radioactivity was measured with liquid scintillation spectrometry, and values were expressed as $\mathrm{dpm} / \mathrm{mg}$ tissue. An early peak for accumulation occurred reproducibly at $10 \mathrm{~s}$ after the injection of both compounds, so this time interval was chosen for the remaining experiments (data not shown). In normal 7-day-old pups the total accumulation and regional distribution were similar with both tracers. Brainstem concentrations were two-fold higher than those in striatum and frontolateral cortex, as expected for blood flow in immature animals $[1,18]$. Using this method, hypercarbia $\left(\mathrm{pCO}_{2}=60\right.$ Torr) doubled the accumulation of $\left[{ }^{3} \mathrm{H}\right]$ flunitrazepam in the brainstem, striatum and cortex of the immature animals $(P<0.01, \mathrm{n}=5)$. Inter-animal differences associated with variation in systemic tracer concentrations could be reduced by 

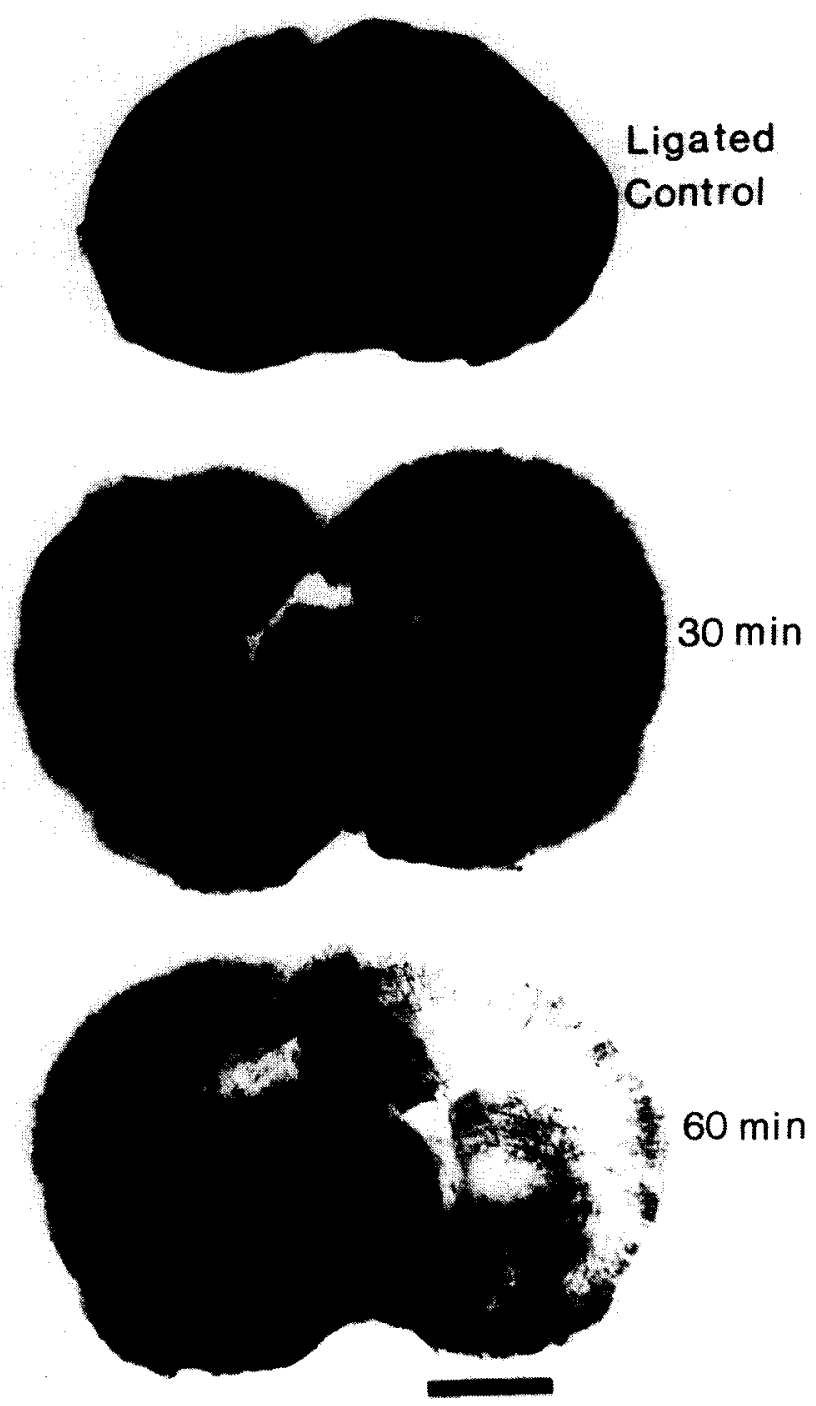

Fig. 1. Cross-sections in India ink perfused brains prepared by injecting $0.2 \mathrm{ml}$ India ink (Koh-i-noor) into the left ventricle $10 \mathrm{~s}$ before sacrifice. Top: 7-day-old pup $3 \mathrm{~h}$ after right carotid ligation without hypoxia. Middle: pup with right carotid ligation and $30 \mathrm{~min}$ of $8 \%$ oxygen, showing decreased perfusion in the right periventricular zone. Bottom: pup with right carotid ligation and exposure to 60 min of $8 \%$ $\mathrm{O}_{2}$, showing marked decrease in perfusion throughout the hemisphere on the side of ligation. The control selection was cut at a slightly more rostral level than the other two. Calibration bar $=2 \mathrm{~mm}$.

calculating the ratios of tracer accumulated in striatum or cortex to that in brainstem; in the rat, the vertebro-basilar arteries supply the brainstem. The striatum:brainstem ratio remained relatively constant $(0.5 \pm 0.05)$ in untreated 
animals or those exposed to hypoxia without ligation. Accordingly, the data were normalized with respect to the brainstem tracer extraction in subsequent experiments.

Hypoxic-carotid ligated pups were studied in this way after $2 \mathrm{~h}$ of hypoxia and compared to unoperated, and unilaterally ligated normoxic controls (Table I). For $\left[{ }^{14} \mathrm{C}\right] \mathrm{IAP}$, the striatum:brainstem ratios were symmetrical in unoperated controls, and unilateral carotid ligation reduced accumulation modestly on the operated side (20\% decrease, $P<0.05$ ). The combination of $2 \mathrm{~h}$ of hypoxia and unilateral carotid ligation reduced striatal tracer extraction by $71 \%$ compared with the contralateral side, which always remained close to values in unoperated controls. Exposure of unoperated pups to $2 \mathrm{~h}$ of $8 \%$ oxygen produced no change in tracer accumulation. The results for cerebral cortex using $\left[{ }^{14} \mathrm{C}\right] \mathrm{IAP}$ and $\left[{ }^{3} \mathrm{H}\right]$ flunitrazepam paralleled closely the striatal changes (Table I). Therefore, these quantitative results agree with the qualitative India ink perfusion studies in showing that hypoxia, combined with carotid ligation, greatly diminishes perfusion in the ipsilateral cerebral hemisphere.

The time-course of this effect was also studied (Fig. 2). As suggested by the India ink injections, hypoxia superimposed on the carotid ligation caused a gradual reduction in isotope accumulation on the ligated side, reaching a nadir at $120 \mathrm{~min}$. The reduction in the perfusion occurs earlier than the time required to produce gross morphologic damage. This occurs between 1 and $1.5 \mathrm{~h}$ of hypoxia in this preparation [15]. We have also described an abrupt time-dependent increase in striatal dopamine turnover in this model [15], and this effect also lags behind the reductions in perfusion.

In the adult rat with unilateral carotid ligation exposed to hypoxia (Levine preparation) [9], Salford et al. [13] found that cerebral blood flow increases bilaterally - four-fold on the side opposite ligation, and doubling on the side of liga-

\section{TABLE 1}

STRIATUM:BRAINSTEM AND CORTEX:BRAINSTEM RATIOS FOR ACCUMULATION OI TRACER IN CONTROL AND TREATED ANIMALS

RCCL, right common carotid ligation. Values are means \pm S.E.M. ${ }^{*} P<0.05$, Student's $t$-test comparing values from right and left sides. ${ }^{* *} P<0.01$, Student's $t$-test comparing values from right and left sides.

\begin{tabular}{|c|c|c|c|c|c|}
\hline \multirow[t]{2}{*}{ Treatment } & \multirow[t]{2}{*}{$n$} & \multicolumn{2}{|c|}{ Striatum:brainstem ratio } & \multicolumn{2}{|c|}{ Cortex:brainstem ratio } \\
\hline & & Left & Right & Left & Right \\
\hline \multicolumn{6}{|l|}{ A: $\left[{ }^{14} \mathrm{C}\right]$ iodoantipyrine } \\
\hline Control & 8 & $0.50 \pm 0.05$ & $0.49 \pm 0.04$ & $0.49 \pm 0.05$ & $0.43 \pm 0.02$ \\
\hline $\mathrm{RCCL}$ & 8 & $0.46 \pm 0.04$ & $0.37 \pm 0.05^{*}$ & $0.52 \pm 0.04$ & $0.35 \pm 0.04$ \\
\hline $\mathrm{RCCL}$ and $2 \mathrm{~h}$ of $8 \% \mathrm{O}_{2}$ & 10 & $0.48 \pm 0.05$ & $0.14 \pm 0.02 * *$ & $0.54 \pm 0.05$ & $0.20 \pm 0.04$ \\
\hline \multicolumn{6}{|l|}{ B: $\left[{ }^{3} \mathrm{H}\right]$ flunitrazepam } \\
\hline Control & 7 & $0.5 \pm 0.04$ & $0.42 \pm 0.05$ & $0.49 \pm 0.06$ & $0.42 \pm 0.06$ \\
\hline $\mathrm{RCCL}$ and $2 \mathrm{~h}$ of $8 \% \mathrm{O}_{2}$ & 4 & $0.46 \pm 0.03$ & $0.25 \pm 0.04 *$ & $0.51 \pm 0.01$ & $0.39 \pm 0.05$ \\
\hline
\end{tabular}




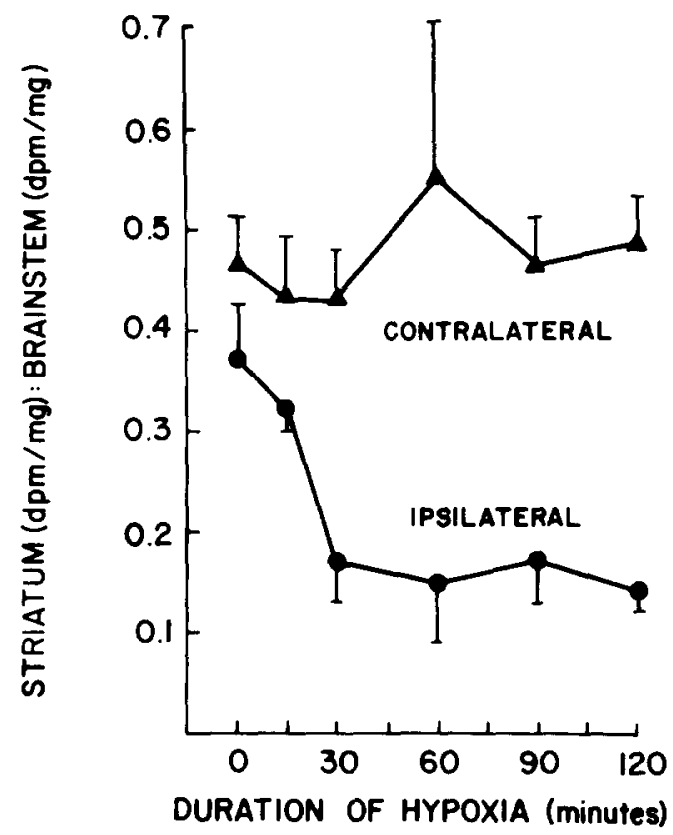

Fig. 2. Time course for accumulation of $\left({ }^{14} \mathrm{Cliodoantipyrine}\right.$ in the corpus striatum of hypoxicunilaterally carotid ligated 7-day-old rat pups. One $\mu \mathrm{Ci}$ of isotope was injected into the left ventricle of the heart at intervals over the $2 \mathrm{~h}$ hypoxic period and the pups were decapitated $10 \mathrm{~s}$ later. Results are expressed as the ratio of $\mathrm{dpm} / \mathrm{mg}$ tissue extracted in the striatum to the $\mathrm{dpm} / \mathrm{mg}$ extracted into the brainstem. Values are mean \pm S.E.M., $n=3-6$ except for $120 \mathrm{~min}$ where $\mathrm{n}=10$. Ipsilateral refers to the side of ligation and contralateral to the opposite side of the brain.

tion. The pathology resulting from this insult was attributed to the effects of 'relative ischemia'. Our data suggest that unilateral carotid ligation and moderate hypoxia in immature rats cause absolute ischemia in the ligated hemisphere. Although the small size of the pups precluded accurate measurement of arterial concentrations of the labelled compound for calculation of absolute blood flow, the uniformity of the grouped data suggests that they provide a reliable estimate of regional perfusion. The failure of hypoxia to stimulate cerebral blood flow [3] suggests that reactivity of cerebral blood vessels to chemical factors may be a developmental acquisition rather than an intrinsic property of the vessels. Recently, Welsh [19] reported that young adult mice exposed to carotid ligation plus $10 \%$ oxygen also developed unilateral cerebral ischemia.

In this preparation the pattern of ischemia that we delineated corresponds well to the distribution of histopathology in animals raised to 8 weeks of age. The corpus striatum is a major target area for later histologic damage in this model [7] and our present results suggest that the pathologic lesion can, at least in part, be attributed to the effects of ischemia. A similar pattern of striatal injury - status marmoratus - has been described in asphyxiated infants. Prominent periventricular destruction 
[2] as well as cortical lesions in asphyxiated infants has also been ascribed to ischemia in vascular watersheds [17]. Thus the blood flow changes in the rat pup model reproduce important events in the pathogenesis of brain injury in human perinatal asphyxia. The mechanism of these effects (e.g. vasospasm, brain edema) is uncertain. Although the systemic circulation remains relatively stable during the experiment [18], systemic hypotension may contribute. Primary depression of neuronal activity could also have contributed since flow is generally coupled to changes in metabolic demands. However, this explanation is unlikely to account for the entire reduction in perfusion because flow changes anteceded other histologic and biochemical abnormalities.

The sequence of events that leads to irreversible neuronal injury has not been well defined. Massive increase in intracellular calcium may be the final common pathway for cell death [14], and increased calcium entry leading to arterial spasm could also play a role in hypoxia-induced ischemia. The infant rat preparation is a useful system for exploring these events.

Supported in part by Grant NS R017542 from N.I.H., Grant R326 from United Cerebral Palsy Research and Education Foundation, and T.I.D.A. NS00603 from NINCDS (M.V.J.). F.S.S. has a fellowship from the Medical Research Council of Canada.

1 Ashwal, S., Majcher, J.S., Vain, N. and Longo, L.D., Patterns of fetal lamb regional cerebral blood flow during and after prolonged hypoxia, Pediatr. Res., 14 (1980) 1104-1110.

2 Banker, B.Q. and Larroche, J.-C.. Periventricular leukomalacia of infancy, Arch. Neurol. 7, (1962) 32.

3 Borgstrom, L., Johannsson, $\mathrm{H}$. and Siesjo, B.K. The relationship between arterial $\mathrm{PO}_{2}$ and cerebral blood flow in hypoxic hypoxia, Acta Physiol. Scand., 93 (1975) 423-432.

4 Courville, C.B., Cerebral Anoxia, San Lucas Press, Los Angeles, CA, 1953.

5 Gjedde, A., Drews, L. and Christensen, B., Brain uptake of a 'Fluid Microsphere': comparison of flunitrazepam, water, and iodoantipyrine transfer across blood-brain barrier, J. Cereb. Blood Flow Metab., 3:SI (1983) 73-74.

6 Hill, A. and Volpe, J., Seizures, hypoxic-ischemic brain injury, and intraventricular hemorrhage in the newborn, Ann. Neurol., 10 (1981) 109-121.

7 Johnston, M.V., Neurotransmitter alterations in a model of perinatal hypoxic-ischemic brain injury, Ann. Neurol., 13 (1983) 511-518.

8 Kennedy, C., Grave, J.D., Jehle, J.W. and Sokoloff, L., Changes in blood flow in the component structures of the dog brain during postnatal maturation, J. Neurochem., 19 (1972) 2423-2433.

9 Levine, S., Anoxic-ischemic encephalopathy in rats, Amer. J. Pathol., 36 (1960) 1-17.

10 Myers, R.E., Experimental models of perinatal brain damage: relevance to human pathology, ln: L. Gluck (Ed.), Intrauterine Asphyxia and the Developing Fetal Brain, Yearbook Medical Publishers, Inc., Chicago, 1977, pp. 37-97.

11 Rice, III, J.E., Vannucci, R.C. and Brierly, J.B. The influence of immaturity on hypoxic-ischemic brain damage in the rat, Ann. Neurol., 9 (1981) 131-141.

12 Sakurada, O., Kennedy, C., Jehle, J., Brown, J.D., Carbin, G.L. and Sokoloff, L., Measurement of local cerebral blood flow with iodo $\left[{ }^{14} \mathrm{C}\right]$ antipyrine, Amer. J. Physiol., 234 (1978) H59-H66.

13 Salford, L.G. and Siesjo, B.K., The influence of arterial hypoxia and unilateral carotid artery occlu- 
sion upon regional blood flow and metabolism in the rat brain, Acta physiol. scand., 92 (1974) 130-141.

14 Schanne, F.A.X., Kane, A.B., Young, E.E. and Farber, J.L., Calcium dependence of toxic cell death: a final common pathway, Science, 206 (1979) 700-702.

15 Silverstein, F. and Johnston, M.V., Effects of hypoxia-ischemia on monoamine metabolism in the immature brain, Ann. Neurol., 15 (1984) 342-347.

16 Volpe, J. and Pasternak, J., Parasagittal cerebral injury in neonatal hypoxic-ischemic encephalopathy. Clinical and neuroradiologic features, J. Pediatr., 91 (1977) 472-475.

17 Volpe, J.J., Cerebral blood flow in the newborn infant: relation to hypoxic-ischemic brain injury and periventricular hemmorrhage, J. Pediatr., 94 (1979) 170-173.

18 Welsh, F.A., Vannucci, R.C. and Brierley, J.B., Columnar alterations of NADH fluorescence during hypoxia-ischemia in immature rat brain, J. Cereb. Blood Flow Metab., 2 (1982) 221-228.

19 Welsh, F.A., Sims, R.E. and McKee, A.E., Effects of glucose on recovery of energy metabolism following hypoxia-oligemia in mouse brain: dose dependence and carbohydrate specificity, J. Cereb. Blood Flow Metab., 3 (1983) 486-492. 